\title{
La niñez chilena exiliada en Buenos Aires. La escuela como ventana a la experiencia infantil (1974-1983)
}

Chilean children exiled in Buenos Aires. The school as a window to the children's experience (1974-1983)

Natalia Casola

Instituto Interdisciplinario de Estudios de Género/CONICET, Argentina

nataliacasola@hotmail.com

\section{Resumen:}

Este artículo analiza la experiencia de la niñez chilena exiliada en Buenos Aires durante el tercer gobierno peronista y la última dictadura militar. Un porcentaje significativo de esos niños fueron asistidos junto con sus familias por la Comisión Argentina para los Refugiados (CAREF), una agencia humanitaria creada en los últimos meses de 1973 para ayudar a los chilenos que diariamente cruzaban la frontera escapando a la represión de la dictadura de Pinochet. La mayoría de esos niños en Capital Federal fueron admitidos en la escuela primaria de orientación protestante Laura y Henri Fishbach, que decidió, en acuerdo con CAREF, implementar un proyecto de integración destinado a la equiparación académica y a la socialización afectiva del grupo refugiado. En este artículo demostraremos 1) que muchos de los problemas que presentaba la población infantil eran efecto del contexto represivo sufrido tanto en Chile como Argentina; 2) que el paso por la escuela cumplió una función de contención significativa en la vida de los niños y; 3) que el proyecto de la institución debe entenderse tomando en cuenta la adhesión explícita de los directivos y docentes a las pedagogías críticas.

Palabras ClaVe: Infancia, Represión, Refugiados, Escuela, Pedagogías críticas.

\section{AbstraCt:}

This article analyzes the experience of Chilean children exiled in Buenos Aires during the third Peronist government and the last military dictatorship. A significant percentage of these children were assisted together with their families by the Argentine Commission for Refugees (CAREF), a humanitarian agency created in the last months of 1973 to help Chileans who crossed the border daily, escaping the repression of the dictatorship of Pinochet. The majority of these children in Capital Federal were admitted to the evangelically oriented primary school, "Laura and Henri Fishbach", which decided, in agreement with CAREF, to implement an integration project aimed at academic equalization and affective socialization of the refugee group. In this article we will show 1) that many of the problems presented by the child population were an effect of the repressive context suffered both in Chile and Argentina; 2) that the passage through the school fulfilled a function of significant containment in the lives of the children and; 3) that the project of the institution should be understood taking into account the explicit adherence of managers and teachers to critical pedagogies.

KeYWORDS: Childhood, Repression, Refugees, School, Critical pedagogies.

La historia de la infancia chilena exiliada en Argentina durante la dictadura de Pinochet (1973-1990) aun no ha sido contada. En este artículo nos proponemos comenzar a visibilizar esta experiencia a partir del estudio del caso de los niños (varones y mujeres) albergados, junto a sus familias, en hoteles y casas de refugio de la Capital Federal bajo la protección de la Comisión Argentina para los Refugiados (CAREF), una agencia humanitaria fundada en 1973 por un conjunto de iglesias protestantes para asistir a las necesidades del exilio latinoamericano en el país. Un porcentaje significativo de esa población infantil asistió desde marzo de 1975 a la escuela primaria Laura y Henri Fishbach, perteneciente al Centro de Orientación para la Vida Familiar y Comunitaria de Villa Mitre (COVIFAC), como parte de una experiencia educativa piloto que se mantuvo vigente en los años siguientes para dar respuesta a la necesidad

Recepción: 19 de agosto de 2018 | Aprobación: 04 de febrero de 2019 | Publicación: 28 de mayo de 2019 
de escolarizar a los niños y favorecer su socialización en un contexto atravesado por una alta exposición a la violencia.

En esta oportunidad nos preguntamos por los efectos del contexto represivo en la experiencia infantil y por la manera en que el paso por la institución escolar transformó la subjetividad de los niños en el exilio. La mayoría de las familias chilenas que cruzaron la frontera llegaron a la Argentina escapando de la persecución y la violencia. Sin embargo, encontraron un país cuyo contexto se parecía cada vez más al que habían dejado atrás. Desde agosto de 1974 las posibilidades de radicarse legalmente en Argentina quedaron canceladas y nuestro país se transformó en un lugar de tránsito mientras esperaban una visa para poder salir hacia un tercer destino. Las familias con status de refugio asignado por el Alto Comisionado de las Naciones Unidas para los Refugiados (ACNUR) podían beneficiarse de los programas de asistencia material de los que participaba CAREF. No obstante, esta situación suponía un "arma de doble filo" toda vez que ser refugiado conformaba una condición autoincriminante a los ojos de los aparatos de vigilancia y represión del Estado. ${ }^{1}$ Durante los años del gobierno peronista y de la dictadura militar, los refugios fueron allanados en varias oportunidades y los niños quedaron sujetos a nuevas situaciones de violencia que alteraban las rutinas y atentaban contra la reconstrucción de una vida segura en Buenos Aires (Casola, 2017 y 2017a). En este contexto, sostenemos que la escuela cumplió un rol fundamental para la socialización y estabilidad afectiva de la población infantil.

Nuestra hipótesis fundamental es que la política del gobierno peronista (desde mediados de 1974) y de la dictadura militar restringieron severamente las condiciones de vida de las familias exiliadas con el propósito de acelerar su expulsión del país. Una de las dimensiones sociales afectadas fue la escolarización de los niños extranjeros, lo que provocó una profundización en el deterioro académico y afectivo.

La segunda hipótesis que sostenemos es que para dar respuesta a la política expulsiva del Estado, CAREF y la Escuela de Villa Mitre diseñaron un proyecto piloto a medida de los niños refugiados que produjo transformaciones visibles en las subjetividades de la población infantil, ayudando a contrarrestar los efectos traumáticos del exilio.

El presente trabajo es parte de una investigación en progreso sobre la evolución de la política del Estado hacia los exiliados chilenos entre 1973 y 1990 y de la vida cotidiana del exilio en Buenos Aires. En dicho recorrido hemos podido detectar la especificidad de la experiencia infantil y la necesidad de analizarla tomando en cuenta sus particularidades y formas de protagonismo.

En este caso trabajamos con fuentes documentales y fotográficas del archivo histórico de CAREF y con entrevistas orales. La mayoría de los documentos consisten en informes de la psicóloga escolar que hacía el seguimiento de los casos de los niños refugiados, además de informes y balances anuales elaborados por la asistente social de CAREF para registrar y rendir cuentas ante la Comisión Directiva de la institución sobre la marcha del proyecto educativo. Tales documentos nos permiten conocer muchos aspectos de la vida infantil en el exilio, de sus dificultades, pero también de sus formas de participar y significar la experiencia tanto en el ámbito familiar como en la escuela. Nuestra perspectiva de análisis, por tanto, suscribe a la visión que se ha vuelto predominante en el campo interdisciplinar de los estudios de las infancias, que aspira a encontrar en la voz de los niños un modo particular de participar en los hechos sociales Castillo-Gallardo y González-Celis, 2015). Se trata entonces de reconocer que los infantes son agentes activos de sus propias vidas, aun en el marco de su subalternidad, en la medida que pesan sobre ellos condicionantes estructurales que provienen del mundo adulto. En el campo de los estudios sobre los exilios la reconstrucción de la experiencia infantil también se ha vuelto relevante en los últimos años. Tradicionalmente los relatos sobre los exilios políticos se concentraron alrededor de la representación de los exiliados como sujetos adultos, eminentemente masculinos y militantes. Esas representaciones, recurrentemente, omitieron la presencia de otros sujetos que por su carácter subalterno fueron invisibilizados, tanto con relación a los efectos traumáticos como al plus político que en ocasiones produjo la experiencia (Burgos Fonseca, 2018, p. 224). ${ }^{2}$

Con relación a las fuentes, es necesario aclarar que presentan el problema de que la voz infantil aparece mediatizada y doblemente sesgada: a) por la mirada adulta y b) por la mirada adulta en el marco de 
instituciones que, a su vez, rendían cuentas ante potenciales y reales controles del Estado. Sin embargo, aun con esas limitaciones y los cuidados metodológicos que se desprenden, pensamos que constituyen una ventana al mundo de la niñez exiliada ${ }^{3}$ cuyas voces son difíciles de recuperar por la oralidad, considerando el carácter transitorio de su permanencia en Argentina y la diáspora posterior. Algunos de los informes describen situaciones de conflicto pero también detallan progresos académicos o sociales que permiten reconstruir las tácticas implementadas por los niños para participar en forma activa (aunque muchas veces eso significaba resistencia) de los planes que el mundo adulto les reservaba. Es decir, muchas situaciones narradas dan cuenta que los niños vivían el exilio con cierto nivel de consciencia (no necesariamente de información) respecto de sus condiciones "excepcionales" de existencia y que luego las trasladaban a la escuela de diverso modo. Pero, también, las fuentes son indicadoras de las representaciones y prácticas que la institución escolar tenía sobre ellos y de las estrategias construidas para lidiar con los conflictos que suponía la presencia de refugiados. Por ejemplo, muchos de estos documentos resultan valiosos porque permiten observar que al menos idealmente la escuela buscaba ofrecer mucho más que contención y aspiraba a producir efectos académicos y sociales significativos que les permitiera "recuperar" la infancia. ${ }^{4}$ No obstante, los documentos también son reveladores de las dificultades que los adultos encontraron, en este caso como educadores, para sostener su rol de autoridad y cuidado ante un grupo que afrontaba experiencias extremas que ellos mismos no tenían. Pese a todo, sostenemos que este proyecto, aun con sus limitaciones, resulta doblemente interesante si tomamos en cuenta que se desarrolló en un contexto autoritario y contrario, al menos oficialmente, a las pedagogías críticas. ${ }^{5}$ Sostenemos que la escuela de Villa Mitre tenía motivos para ser cautelosa porque su reconocimiento social previo había sido construido con base en su concepción liberal, progresista y de inspiración marxista. Entonces, la decisión institucional de no interrumpir el programa con refugiados conformó una decisión que no debe minusvalorarse, en especial, porque los contextos represivos, por propio efecto del terror, suelen quebrar lazos sociales solidarios aun en los espacios más impensados. La continuidad en las líneas de trabajo fundamentales, por tanto, ponen de manifiesto aquello que otros autores ya han señalado: que junto con la represión, también aparecieron estrategias de resistencia -organizadas o espontáneas- de los diversos actores dentro del propio sistema educativo (Pineau y Mariño, 2006).

Volviendo a las fuentes utilizadas para esta investigación, cabe decir que también hemos utilizado fotografías porque conforman un testimonio más directo de la experiencia escolar, aunque, desde luego, resulte imposible reconstruir los contextos específicos en que fueron retratadas las escenas. Con todo, muchas de estas imágenes nos muestran numerosos rasgos de la vida institucional valiosos para cotejar con las memorias documentales y orales. En estos casos, intentaremos evitar la utilización de las fotografías de modo meramente ilustrativo. Siguiendo las advertencias ya clásicas entre los investigadores sociales de la fotografía, nuestra apuesta será desentrañar una serie de cuestiones en torno de su contenido y contexto de producción: ¿qué nos muestran las fotografías?, ¿quiénes nos muestran? y ¿cómo nos muestran? (Triquell, 2012). La mayoría de las fotografías fueron catalogadas muy recientemente en CAREF como parte de un esfuerzo de conservación del patrimonio histórico más general que los puso en contacto con el Archivo Nacional de la Memoria.

Por último, las entrevistas realizadas como resultado de una primera aproximación al tema, además de permitirnos completar aspectos que no aparecen en la documentación, también nos acerca a la memoria de aquella experiencia, un aspecto en que no vamos a ahondar en esta oportunidad pero que podríamos explorar en el futuro.

En la primera parte de este trabajo vamos a repasar algunos aspectos generales de la situación de los exiliados chilenos en nuestro país a partir de fines de 1973 con el propósito de situar al lector sobre el contexto más general en el que se desenvuelve esta experiencia. Luego, nos adentraremos en el análisis de nuestro caso, el de los niños de "la Villa Mitre", como se conoce popularmente a la escuela. 


\section{El eXilio latinoAmericano en Argentina entre 1973 y 1983}

A grandes rasgos, podemos afirmar que la Argentina se transformó en el destino predilecto para aquellos exiliados (chilenos en su gran mayoría, pero también uruguayos y de otros países de América Latina) que no contaban con recursos económicos suficientes ni contactos políticos para costear un destino máłejano. Podría decirse que Argentina fue el destino principal para el exilio pobre, suficientemente comprometido como para que su vida peligrase pero sin el capital económico o político como para elegir un destino ms seguro.

En un primer momento (septiembre de 1973-agosto de 1974) Argentina todavía podía representar un lugar relativamente apto para los recién llegados. Aunque la acogida nunca fue del todo amable, el gobierno peronista a través de la Dirección Nacional de Migraciones (DNM) dirigida por Lelio Mármora, implementó una serie de medidas dirigidas a la integración de los exiliados: 1) la amnistía de 1974 y 2) la política de asentamiento en las provincias habilitadas por el plan poblacional, que combinaba la posibilidad de establecer residencia en el país con la prohibición de fijarla en Capital Federal y sus alrededores, Córdoba, así como en la franja fronteriza con el país de origen (200 km de ancho) (Azconegui, 2014). Para hacer viable esta política, en abril de 1974 el Estado autorizó la creación de la Comisión Coordinadora de Acción Social (CCAS) la cual, a falta de una estructura propia, centralizaba y coordinaba la acción de organizaciones eclesiásticas para la ayuda y reubicación de los exiliados. En Buenos Aires las organizaciones eran dos, la Comisión Católica Argentina para la Inmigración, CCAI (católicos que contaban con una gran tradición en materia de ayuda a los migrantes y refugiados) y la Comisión Argentina para los Refugiados y Migrantes, CAREF (conformada por una minoría dentro del universo protestante: las iglesias Luterana Unida, Metodista Argentina y del Rio de la Plata a las que se sumaría los Discípulos de Cristo) que recibían financiamiento de ACNUR y del Consejo Mundial de Iglesias (CMI).

A partir del 1 de agosto de 1974 el gobierno peronista tomó la decisión de no otorgar nuevas radicaciones para los chilenos que ingresaran al país desde esa fecha. Desde ese momento, Argentina y más específicamente sus provincias receptoras (Mendoza, Buenos Aires y Neuquén) se transformaron en lugares exclusivamente de tránsito hacia terceros países, mientras los exiliados esperaban que alguna embajada los aceptase. ${ }^{6}$

Desde entonces, las condiciones de supervivencia de los refugiados quedaron seriamente cuestionadas. Imposibilitados de conseguir trabajo, tampoco podían ingresar a sus hijos en las escuelas excepto que contaran con una cantidad de documentación que rara vez traían consigo en las prisas de la huida hacia el exilio ("Normas para estudiantes extranjeros", martes 29 de marzo de 1977, resumen de prensa CAREF). Tanto en provincia de Buenos Aires como en Capital Federal los requisitos burocráticos habían dejado a prácticamente todos los jóvenes refugiados en edad de secundario sin posibilidad de asistir a la escuela. En el ámbito de la Capital Federal la política educativa para los colegios primarios era apenas más flexible y los requerimientos de documentación no alcanzaban a las escuelas privadas, por eso, como veremos más adelante, la Escuela Fishbach pudo transformarse en una opción para las familias refugiadas.

\section{LA ACCIÓN DE CAREF}

Oficialmente CAREF se constituyó el 3 de octubre para servir al refugiado sin discriminación ideológica, brindar ayuda, asistencia social y pastoral como expresión del servicio cristiano de las iglesias.

Su origen debe comprenderse en el marco de la radicalización política de algunas minorías protestantes latinoamericanas que las llevó a impulsar una serie de iniciativas imaginadas como parte de un programa de transformación social integral, en sintonía con el radicalismo cristiano de inspiración marxista propio de la Teología de la Liberación. ${ }^{7}$ La construcción de CAREF, entonces, fue una de las primeras y últimas iniciativas 
de este grupo de pastores. La imposición del terrorismo de Estado, sumado a la fragmentación del mundo protestante, fueron algunas de las razones que obturaron la continuidad de un proyecto político común.

Hasta agosto de 1974, entonces, la acción de CAREF consistió, fundamentalmente, en alojar a los exiliados en hoteles y casas de refugio, gestionar empleos y oportunidades de viviendas en ciudades del interior de la provincia de Buenos Aires (a $200 \mathrm{~km}$ de la Capital Federal) o de otras provincias, de acuerdo a lo que establecía la norma. A partir del 1 de agosto de 1974, en cambio, su tarea se abocó a administrar los refugios de tránsito mientras tramitaban las cuotas de admisión en terceros países.

En un comienzo, CAREF contaba con dos refugios en la Capital Federal. Pero con el transcurrir de 1974 y el cambio en la política oficial debieron ampliar y mejorar la organización de los edificios considerando la masividad que había alcanzado el fenómeno. Hacia finales de 1975 contaban con ocho lugares de refugio en Buenos Aires entre los hogares de la propia agencia ("Fray Cayetano", "Brasil", "Córdoba", "José C. Paz" y "Gowland") y los hoteles (Ilton, Pinot y Rich) alquilados exclusivamente para ese fin. Hacia fines de 1974 la cifra de personas asistidas en Buenos Aires trepaba a 1600 personas, lo que implicaba una presión presupuestaria fenomenal ("Memorándum de Emilio Monti para CMI sobre la Situación de los asilados y refugiados políticos en la Argentina”, octubre de 1974, Caja 04, Archivo CAREF).

Durante todo este periodo la violencia fue un dato permanente en la cotidianidad de los refugiados. A lo largo de 1975 tanto los refugios como los domicilios particulares de los empleados de CAREF comenzaron a ser objeto de allanamientos y amedrentamientos policiales y parapoliciales. Esa situación se prolongó durante la dictadura militar y se tradujo en varios operativos perpetrados por el Ejército sobre las distintas casas de refugio. Sin embargo, el cambio en la orientación política hacia los exiliados permitió que las tareas de asistencia continuaran, siempre que hubiese avances en la reubicación de los refugiados que debían salir del país. $^{8}$

La vida cotidiana en los refugios era complicada. Aunque las necesidades básicas como el abrigo, la comida y el aseo estaban garantizadas, la vida de las familias se desenvolvía en comunidad, un tipo de convivencia que resultaba complejo. La falta de intimidad y de autonomía, sumado a la escasa ocupación en labores de interés individual, tornaba difícil la convivencia y generaba problemas y rencillas personales de todo tipo. Por otro lado, el nivel de violencia cotidiana que sufrían por parte de bandas armadas paraestatales y de la propia Policía había vuelto peligrosa la vida en los refugios. Además, para la inmensa mayoría de los refugiados la salida de Chile había acarreado fracturas emocionales de diversa índole. Familiares que habían quedado presos o que habían sido asesinados, parientes de los que nada se sabía o, simplemente, la incertidumbre sobre el futuro propio, de conjunto, todas estas situaciones afectaban la vida de los exiliados y requerían de un abordaje específico.

A comienzos de 1975 existía en los refugios de Capital Federal y el Conurbano bonaerense una población total de 205 niños y niñas de hasta 12 años de edad. Muchos de ellos tenían menos de 6 años y se intentó incorporarlos a guarderías y jardines de infantes. Pero dado que en aquella época existía poca oferta de establecimientos para la primera infancia y las instituciones privadas eran muy costosas, generalmente, se optaba por prescindir de su escolarización. ${ }^{9}$ Entonces los esfuerzos se concentraron en la inserción de los niños de nivel primario, la franja de población para la que resultaba imprescindible la escolarización. De los 79 niños de nivel primario, 24 habían logrado ser absorbidos por las escuelas públicas porque contaban con la documentación requerida. Para el resto, CAREF comenzó a pensar en un proyecto que los incluyera a todos.

Buscábamos entre las escuelas privadas, religiosas, todas las de alrededor de los refugios, porque tampoco era cuestión que los niños viajaran a cualquier lado. Muchos tenían que repetir porque ninguno había traído certificado de escolaridad, de terminación de grado, o sea que esos detalles no los tenían presentes las familias cuando volaban. Entonces, me fueron devolviendo la propuesta con los lugares que cada institución podía rellenar. Yo no pretendía que fueran todos al mismo colegio pero tampoco quería que solo sirvieran al proyecto económico de la escuela, de tener los grados completos, porque ya en esa época las subvenciones tenían que ver con la cantidad de alumnos que tiene que tener cada grado y si ese cupo no se llenaba no corría la subvención. Entonces, yo estaba bastante desesperada... Yo siempre estaba con una oreja acá y otra en mi casa porque tenía que hacer los trámites de inscripción de mis chicos y ahí se me juntan las dos cosas. Ahí se me ocurrió 
llamar a la esposa del Director de "la Fishbach". La llamo a la esposa de Luis [Parrilla, el Director de la escuela], y le cuento la situación. (...) Ella también era asistente social y tenía mucha experiencia práctica. Al otro día lo llamé y me dijo: 'venite con la lista de chicos'. (Entrevista a María Amelia Silva, Asistente social de CAREF, Buenos Aires, octubre de 2017).

\section{La escuela de Villa Mitre}

La escuela primaria Laura y Henry Fishbach pertenecía al Centro de Orientación para la Vida Familiar y Comunitaria de Villa Mitre (COVIFAC) ${ }^{10}$ Dirigida por el Pastor Luis Parrilla, era una escuela muy reconocida socialmente por los vecinos del barrio de la Paternal por su amplitud ideológica y su propuesta pedagógica progresista.

La escuela había sido fundada en 1964 por la Iglesia de los Discípulos de Cristo y se llamó así en homenaje a un matrimonio de docentes protestantes, Laura y Henry Fishbach, cuya labor se había desarrollado en zonas pobres y barrios latinos de Estados Unidos. ${ }^{11}$ Fue la hija de este matrimonio quien viajó como misionera a Buenos Aires y aceptó financiar la escuela con la condición de que llevara el nombre de sus padres. Las iglesias protestantes históricas tenían una larga trayectoria en la construcción de escuelas. Desde mediados del siglo XIX, en toda América Latina, habían fundado instituciones educativas como un medio para difundir fuera del recinto del templo y de la comunidad protestante valores religiosos y políticos democráticos. ${ }^{12}$ Sin embargo, en el contexto de los años 1960 esa tradición fue resignificada gracias a la influencia de las pedagogías críticas y de la teología de la liberación. Aunque las ideas de raigambre liberal no fueron abandonadas, en especial la valoración de la libertad de expresión como medio de construcción de una ciudadanía democrática, se sumaron las novedades vinculadas a la educación popular como vehículo para la liberación. Como ha demostrado Federico Brugaletta (2017), durante los años 1960 las ideas de Paulo Freire adquirieron gran circulación y notoriedad trascendiendo, inclusive, las fronteras de las comunidades protestantes. La fundación de la escuela Laura y Henri Flishbach, entonces, debe entenderse en ese marco de radicalización política de algunas minorías protestantes que comenzaron a pensar su intervención en una clave política nueva, más radical y comprometida con la realidad social y su potencial transformación.

El proyecto escolar ofrecía una orientación laica, un aspecto que le permitió atraer a familias muy heterogéneas: "La escuela empieza a tener mucha resonancia porque era una escuela laica, siempre fue laica porque la doctrina era 'todos tienen derecho a...'. Así que estaba llena de familias judías. Familias judías comunistas, socialistas, jajaja." (Entrevista a Norma Falchetti, exmaestra de la escuela de Villa Mitre, Buenos Aires, mayo de 2018).

Durante los fines de semana la vida social de la escuela tendía puentes con la del COVIFAC, este sí más estrechamente vinculado con el desarrollo del culto. Los días sábados por la tarde funcionaban las llamadas Ligas, con actividades para los chicos. Durante esas jornadas se hacía deportes, juegos, teatro y paseos. El domingo por la mañana se desarrollaba el culto.

[La base ideológica] Abrevaba en el mensaje de Cristo. Nada más. Un tipo que respira no hacia adentro, sino hacia afuera. Donde el mensaje va caminando por los pueblos, caminando entre la gente. Escuchando y no bajando línea. Ideología que aplica muy fuertemente Paulo Freire en Brasil con la pedagogía del oprimido, la pedagogía de la esperanza. Se trabajó mucho con esto pero, básicamente, te diría es una base evangélica que la toman los católicos con la teología de la liberación. Todo esto pasa en la década de 1960, fue muy fuerte. (...) Puede ser liberado el que conoce, el que piensa, el que descubre, el que cuestiona. Esa era la metodología con los chicos. Nosotros a la mañana, empezábamos todas las mañanas, todos juntos, y Luis Parrilla tenía un pequeñísimo, no mensaje, era como un abrir un pensamiento sobre algún tema que estaba pasando y después en el aula lo íbamos a desarrollar. Entonces, se leían los diarios, se hacían debates, con los más chicos también, todos podían opinar. (Entrevista a Norma Falchetti, exmaestra de la escuela de Villa Mitre, Buenos Aires, mayo de 2018).

Este último recuerdo es interesante porque habla de una escuela que consideraba que los niños eran sujetos con derecho a expresarse. Pensamos que esta idea introducía formas de politización infantil en sintonía con el contexto más general de radicalización social y política de la sociedad y su impacto en la educación. La 
influencia de las pedagogías "críticas" o "democráticas" (Puiggros, 2003, p. 154), en especial de los textos de Paulo Freire, de la psicología social y de las teorías de la recreación (Brugaletta, 2017). ${ }^{13}$ Prácticas de este tipo resultaban innovadoras y muestran la búsqueda por parte de la institución de generar una praxis acorde con sus principios ideológicos. Fue en base a ese proyecto y a la experiencia acumulada en su primera década de vida institucional que la escuela decidió recibir a los niños de las familias refugiadas.

A comienzos de 1975 se incorporó un contingente de 45 alumnos de entre 6 y 12 años de edad. Para estos niños el ingreso a la escuela representaba un cambio cualitativo en sus vidas cotidianas. La institución ofrecía jornada completa, almuerzo y asistencia psicopedagógica. Quiere decir que la jornada completa permitía que de lunes a viernes buena parte de la cotidianidad se desenvolviera en un lugar distinto al del hotel o casa de refugio, sede de la vida familiar pero también objeto de la mirada y la violencia del Estado.

Como los niños presentaban un gran desnivel tanto académico como de integración social, el proyecto de "la Villa Mitre" previó la conformación de espacios multigrados transitorios con maestros niveladores para intentar trabajar sobre las situaciones más difíciles.

Se contrató una docente especial, extranjera, y vino una seño uruguaya para formar un aula multigrado. A la mañana tenían la actividad regular y a la tarde talleres de tutti cuantti. Entonces, a la mañana tenían a la seño uruguaya, no la seño argentina [enfatiza] que para ellos podía ser hasta amenazante. Y ese año se fueron nivelando. Ella tenía como tarea ver qué logros tenían de escolaridad para que luego pudieran incorporarse a los grados que les correspondía. Una tarea muy rica, y que se hacía también con los padres. (Entrevista a María Amelia Silva, Asistente social de CAREF, Buenos Aires, octubre de 2017).

La llegada de los niños refugiados, entonces, supuso un esfuerzo de toda la institución para adaptar espacios y orientar los objetivos. No obstante, la finalidad no era que quedasen en el grado nivelador, sino que pudieran incluirse en los niveles que correspondían a su edad.

En la foto que vemos a continuación podemos observar una situación del aula de $6 .^{\circ}$ grado un día cualquiera de 1976.

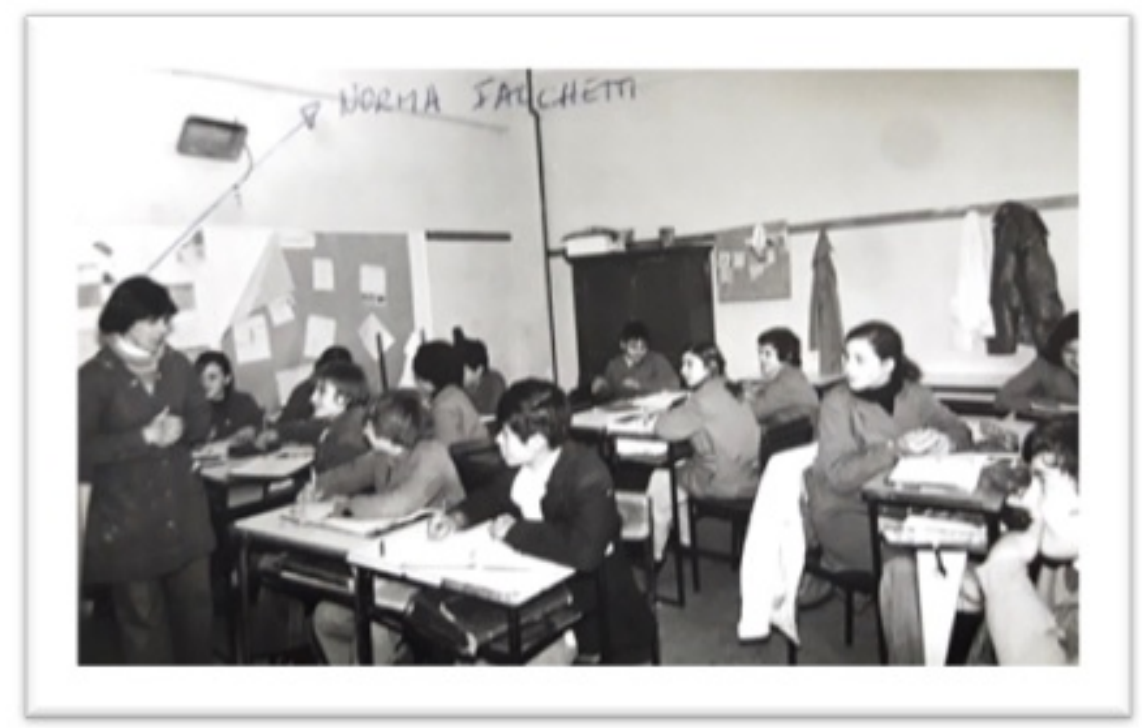

La foto nos muestra una dinámica de trabajo descontracturada. La mayoría de los niños se encuentra trabajando en grupos y no todos parecen llevar el mismo uniforme, a pesar de que se trataba de una institución privada. En las paredes podemos observar la exposición de los trabajos de los niños dispuestos asimétricamente, un detalle que expresa una intencionalidad lúdica. Las expresiones de los niños y niñas son alegres y permiten pensar que la escuela efectivamente era un lugar en el que estaba habilitado el juego y la expresión libre de las individualidades. 


\section{LOS NIÑOS DEL EXILIO}

Los informes que la Directora Técnica de la escuela a cargo del Gabinete de Orientación Pedagógica dirigía a CAREF y los reportes realizados por la psicóloga del colegio (sólo en algunos casos los informes eran redactados por las maestras) son muy reveladores de los problemas sociales, psicológicos y académicos que arrastraban los niños refugiados.

Estos niños se hallan en tránsito en nuestro país por lo que los objetivos establecidos son de carácter inmediato (...) Si bien este grupo comparte una problemática básica (el desarraigo de su medio) existe una heterogeneidad en cuanto a grupos familiares, niveles socioeconómicos, salud, intelectuales, posibilidades de futuro. En general se trata de un grupo con dificultades afectivas, bajo nivel de aprendizaje académico (hay varios casos de niños con más de un año de escolaridad interrumpida; niños de 15 años sin terminar aun $5^{\circ}$ grado; niños de 11 años que no manejan aun la lecto-escritura. ("Informe del Equipo de Orientación pedagógica de la escuela”, 10 de julio de 1975. Caja 20. Educación, Archivo CAREF).

En general, en los informes, los síntomas solían repetirse: deficiente formación por interrupción de la escolaridad, desnutrición, nerviosismo y problemas para integrarse en los grupos. Una de las explicaciones más recurrentes era que las familias llegaban fracturadas y que, por tanto, los niños vivían en condiciones de incertidumbre que explicaban muchos de los trastornos.

Un ejemplo es el informe de Gino de 7 años de edad:

El niño se encuentra en el país solo con el padre. La pareja está separada desde que era muy pequeño. La madre se ha quedado en Chile con una niña menor de 3 años. Estamos notando que la falta de mamá en el niño se manifiesta en algunas necesidades y expresiones volcándose en la maestra como figura femenina. ("Informe de la psicóloga escolar", s/mes, 1977. Caja 20 Educación, Archivo CAREF).

En otras ocasiones, los padres estaban juntos, pero la situación socioeconómica de la que provenían sumado a la interrupción de la escolaridad operaba en contra de una integración escolar armónica. Este era el caso de Jorge, Soledad y Reynaldo:

Se trata de una familia de nivel socio-cultural muy bajo. Los tres niños presentan cuadro de desnutrición y desde el punto de vista escolar, están muy atrasados teniendo en cuenta la edad y el grado alcanzado. Existe un atraso de 3 y 4 años por escolaridad interrumpida y por deficiencia individual. Se está trabajando con la mamá para ayudar a superar los problemas de tipo salud, en principio, desnutrición y problemas en la visión de Soledad. ("Informe de la psicóloga escolar", marzo de 1977. Caja 20 Educación, Archivo CAREF).

En ocasiones, el bajo nivel académico reflejaba trayectorias educativas deficientes de todo el grupo familiar. Un informe de 1978 redactado por una asistente social de CAREF, por ejemplo, señalaba que del total de adultos asistidos, poco más de un $40 \%$ contaba con un nivel de escolaridad primaria completo. Entre un 38 y un $40 \%$ tenía estudios secundarios y solo un $20 \%$ había logrado cursar en alguna universidad (Memoria Anual 1977, CAREF, Caja Actas y reseñas).

Más allá de las particularidades familiares que atravesaban muchos de los niños que habían pasado de vivir en Chile en hogares unifamiliares a vivir en espacios de convivencia compartida, en un país diferente, lo cierto es que buena parte de los problemas académicos, afectivos y sociales que acarreaban eran consecuencia del exilio. Las fracturas de las familias y la interrupción de la escolaridad agravaban condiciones sociales previas generalmente precarias. Por si fuera poco, la llegada a la Argentina no había supuesto solo el desafío de integrarse en una comunidad nacional diferente. En nuestro país vivían bajo una permanente exposición a la violencia y con la consciencia de una permanencia transitoria.

Esas situaciones, el temor a ser atacados y la necesidad de defenderse de esos potenciales ataques eran trasladados a la escuela y se manifestaban de diversas maneras.

Me acuerdo de uno que venía siempre con una sevillana. Entonces a este pibe un día le dije: ¿Sabés lo que pasa? vos estás mal, pero nosotros no estamos mejor. Estamos en la misma. O empezamos a andar bien o va a ser muy difícil. Así que te voy a pedir que me des la sevillana. Yo cuando te vas te la doy pero acá adentro no. Vos mirá acá: ¿quién saca un arma? ¿Para qué 
querés una sevillana? ¿Para sacarle la punta al lápiz? Tomá, te presto un sacapuntas. No tenés ninguna necesidad de tener una sevillana acá. (Entrevista a Norma Falchetti, exmaestra de la escuela. Buenos Aires, mayo de 2018).

El recuerdo de Norma pone de manifiesto que la violencia era una coordenada que atravesaba la historia de estos niños. Sin embargo, también pone de relieve que la escuela era un lugar en donde podían enojarse e incluso exponer que ellos podían contestar a esa violencia. Estas situaciones, por tanto, son reveladoras de la manera que los niños encontraban de actuar lo que les estaba sucediendo. En este sentido, pensamos que la violencia que los niños llevaban a la escuela era menos el resultado de "patologías" individuales y mucho más un efecto del contexto represivo en el que estaban inmersos permanentemente. Reproducir la violencia en el espacio escolar, en este caso, puede interpretarse como una forma de participar del exilio, de defenderse $\mathrm{y}$, por qué no, de mostrar lo que les estaba sucediendo.

\section{UNA EXPERIENCIA TRANSFORMADORA}

A pesar de las condiciones adversas en las que ingresaban, algunos informes dan cuenta de la importancia que tuvo el paso por la escuela en la subjetividad de la población infantil.

Al cabo de tres años Carolina fue venciendo las dificultades que traía y pudo superar su nivel deficiente, que sin duda tenía que ver con el deterioro ocasionado por las experiencias vividas y la falta de escolaridad. Carolina ha ido cambiando su manera de ser, de una niña tímida y asustadiza se fue transformando en una niña alegre, espontánea pudiendo desarrollar todas sus capacidades. (...) Al partir hacia Europa Carolina dejó una carta sumamente emotiva y profunda para sus maestros y compañeros, que muestran el significado de las experiencias vividas aquí. ("Informe de la maestra", Julio de 1976. Caja 20 Educación, Archivo CAREF).

En este caso podemos ver que la escuela y los espacios de sociabilidad organizados en torno de ella ofrecían una alternativa de integración y desarrollo individual que compensaba las carencias y dificultades de la vida en el refugio. Aunque la experiencia de Carolina fue más larga que la de otros que partieron al poco tiempo, resulta reveladora de la capacidad que tenía la escuela para ofrecer una rutina y la posibilidad de construir pertenencia con un lugar en el que se sabían de paso. Más tarde o más temprano, el problema de la partida del país estaba presente, lo que colocaba a los niños y a la escuela en la situación de tener que volver a despedirse:

En septiembre de 1976 el Señor Gusmán viaja a Europa viendo como posibilidad lograr posteriormente la salida de su familia. En todo este año la Sra. y sus tres hijos vivieron la experiencia de la inseguridad de lograr el reencuentro. Ella trató de trabajar y de mantener la esperanza de una solución; finalmente el señor logró que la familia se reuniera con él en Europa habiendo pasado un año. ("Informe de la maestra”, Julio de 1976. Caja 20 Educación, Archivo CAREF).

Paradójicamente, ante estos casos, inevitables porque la política del Estado era impedir que los refugiados permanecieran dentro del país, despedirse resultaba difícil. Pensamos que esa dificultad pone de manifiesto que la escuela efectivamente funcionó como un eje que organizó la vida de los niños y los contuvo emocionalmente.

\section{INTEGRARSE CON EL OTRO}

Uno de los aspectos que debió encarar la escuela fue el de la integración de los niños a la comunidad de argentinos. En la siguiente foto, a la que accedimos en el momento de la entrevista con Norma, podemos observar a Rodrigo, uno de los niños refugiados. 


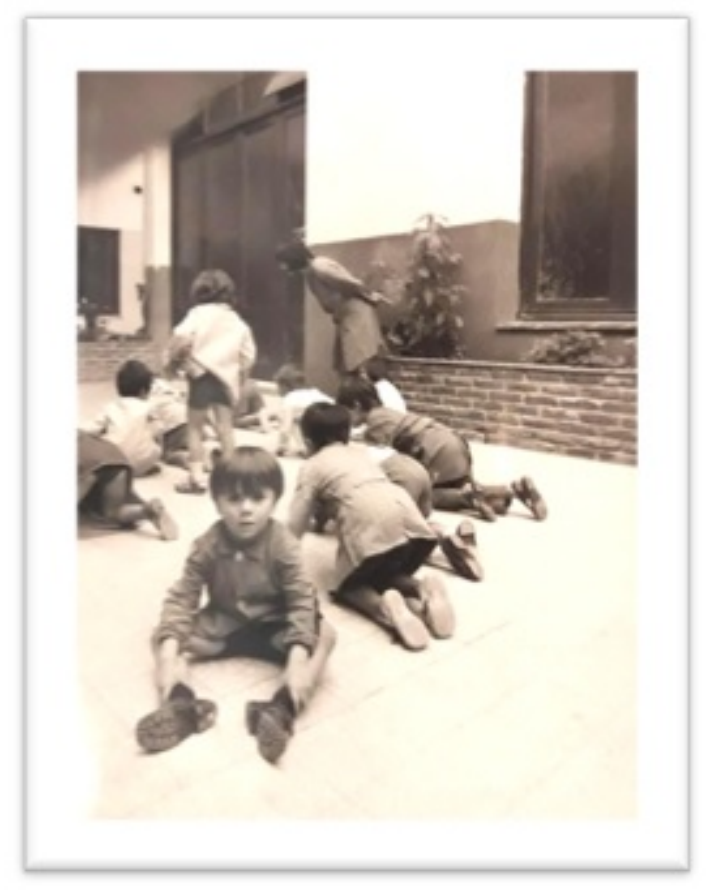

En la imagen es posible observar a un grupo de niños jugando en el patio del colegio posiblemente durante alguno de los recreos. Sin embargo, uno de ellos está en la escena pero no está participando del juego. Ese niño es Rodrigo a quien vemos posar para la cámara desentendiéndose de la actividad central que entretiene al resto del grupo y captura la atención de la maestra. ¿Acaso está en otro juego con la persona que fotografía? ¿Es esta foto un pequeño registro de una forma de inserción periférica?

En el siguiente informe que evalúa la situación general de los niños refugiados la institución admite que debieron afrontar problemas en la integración.

Se experimenta un proceso de integración donde juegan dos grupos humanos los niños refugiados y los de nuestra comunidad. En esta situación se debe tener en cuenta también, las expectativas y acciones del personal. ("Informe del Equipo de Orientación pedagógica de la escuela”, 10 de julio de 1975. Caja 20, Educación. Archivo CAREF).

Aunque la escuela era reconocida por su progresismo y solidaridad con el otro, lo cierto es que los niños refugiados tenían características distintas respecto de los argentinos. No solo hablaban diferente, la mayoría provenía de sectores pobres de Chile y, por si todo esto fuera poco, habían pasado por experiencias traumáticas que la mayoría de los niños argentinos no conocía ni imaginaba.

Para ir logrando una integración debieron aflorar problemas diversos que se expresaron en agresiones varias, que fueron analizadas y canalizadas a través de asambleas o actividades específicas, donde mostraron las actitudes del grupo nuevo y las simultáneas que se daban en el grupo base. Es natural que se muestre una actitud de rechazo de uno y otro grupo como posibilidad de conexión y posterior aceptación. (“Informe del Equipo de Orientación pedagógica de la escuela”, 10 de julio de 1975. Caja 20, Educación. Archivo CAREF).

Este informe resulta muy curioso porque es prácticamente el único que describe situaciones de conflicto entre los niños argentinos y chilenos en términos globales. En general, los informes individuales y balances grupales ponían el foco en los problemas de los niños refugiados (en casi todos se manifiesta problemas de integración social) sin reparar en las dificultades que manifestaban los alumnos argentinos para integrarlos en la comunidad escolar. Por eso, este informe resulta revelador en la medida que admite que la escuela debió intervenir activamente para producir el encuentro entre los niños. 
Luego de las asambleas de tomas de conciencia de la realidad que estaban viviendo, los argentinos comenzaron a interesarse sanamente por la problemática del niño chileno, pudiendo formarse equipos de trabajo integrados sin dificultad. ("Informe del Equipo de Orientación pedagógica de la escuela”, 10 de julio de 1975. Caja 20, Educación. Archivo CAREF).

El informe permite ver que la escuela intervenía y sostenía una actitud activa para favorecer la integración que se tradujo en la conformación de las asambleas. Como ya hemos dicho, la constitución de estos espacios habla de la influencia de las nuevas pedagogías en boga durante los años 1960 y de la valorización de los niños como sujetos con capacidad de participar de su propia transformación. Sin embargo, pensamos que la realidad debió ser más compleja.

Era difícil. Yo tenía $6 .^{\circ}$ y $7^{\circ}$, con mi compañera, teníamos un salón multiuso que tuvimos que transformarla en aula porque eran muchísimos. Las aulas estaban pensadas para no más de 25 chicos y de repente teníamos 40 y había que trabajar la integración. Además, pobrecitos, eran chicos que no sabían ni por qué estaban ahí. (...) Con los más chiquitos fue más fácil porque se adaptan más rápido. Los más grandes estaban en la actitud de ey por qué tenemos que estar acá? (Entrevista a Norma Falchetti, exmaestra de la escuela. Buenos Aires, mayo de 2018).

Aunque la escuela favorecía la diversidad y la comunidad de padres parece haber participado de los mismos valores, la presencia de los refugiados y sus problemáticas debió ser un elemento disruptivo en la cotidianidad de los niños argentinos que no habían tenido que pasar por experiencias como el desarraigo y la violencia cotidiana. La mayoría de los niños pertenecía social y materialmente a un mundo de familias de clase media porteña con rutinas predecibles y expectativas de ascenso futuro. Entonces, es posible pensar que para los alumnos regulares de la escuela la presencia de los refugiados supuso un factor de encuentro con lo desconocido. Si bien muchos de los niños eran hijos de familias militantes y es posible que en el contexto instalado desde finales de 1974 hayan tenido que modificar comportamientos, lo cierto es que seguían estando en su país, en su escuela. Por otro lado, también es posible hipotetizar que el contexto autoritario y el clima de fomento oficial de las actitudes xenófobas haya calado en algunas familias operando contra la integración de los niños refugiados.

Pero otro aspecto interesante del testimonio recabado es que también pone de relieve los desafíos que afrontaban las docentes para llevar adelante una tarea de tales características. En este punto pensamos que se trataba de un verdadero encuentro entre la teoría (la influencia de la pedagogías críticas) y la práctica, en suma, la producción de una experiencia.

\section{ENTRE LAS PEDAgOGÍAS CRÍTICAS Y LOS ENFOQUES "PSI"}

Un aspecto interesante es que aunque los informes señalados solían explicar las dificultades por el contexto social que traían los niños, rara vez se los ponía en relación con la labor institucional que, de esta manera, quedaba por fuera de la evaluación. Es posible pensar que la revisión de las propias prácticas se producía en espacios que no dejaban marcas burocráticas, en especial si tomamos en cuenta el contexto represivo y poco amigable para las pedagogías experimentales. Sin embargo, pensamos que también podría explicarse por la mixtura de influencias. Dicho de otra manera, sostenemos que el impacto de las pedagogías críticas puede observarse tanto en el desafío asumido por la escuela para al grupo de niños refugiados, como en la conformación de un servicio de orientación con la incorporación de una psicóloga concebida como un actor partícipe de los planes y proyectos institucionales considerados en su totalidad. No obstante, la influencia de los enfoques "psi”, en especial de la de la psicometría -como herramienta para evaluar el desempeño estudiantil y de organización de las prácticas escolares- desvirtuaron los objetivos originales tendiendo a explicar las problemáticas de los niños en términos de insuficiencias individuales en lugar de hacerlo por su contexto. ${ }^{14}$

Los informes elaborados por la psicóloga escolar generalmente seguían la siguiente secuencia: en primer lugar, volcaban los resultados del test Raven, más conocido como test de inteligencia, que servía como 
indicador del nivel académico alcanzado. A partir de estos datos se decidía si el niño en cuestión estaba en condiciones de ingresar al grado que le correspondía de acuerdo con su edad biológica. Recién al final del informe se describía la situación familiar y las formas de socialización con los pares. Muchos de estos informes volcaban diagnósticos y un alto porcentaje determinaban transtornos graves. Veamos algunos ejemplos:

Alexis, 7 años, 1er grado. Concurrió a la escuela de marzo a junio [1975], fecha en que salió del país. [Nótese que el periodo evaluado es relativamente corto, no obstante lo cual el informe afirmaba:]

La estructura de personalidad de Alexis es esquizoide, con una ansiedad persecutoria muy grande. Como defensa ante ésta, se desconecta de la realidad, no se comunica. El niño repite su actitud despectiva y desagradecida, lo que los padres hacen con la institución que los protege. Para el niño y para los padres, el presente está lleno de fantasías y en todos lados se sienten perseguidos. El pronóstico no es bueno, ya que los padres no pueden reconocer que el hijo está enfermo y niegan la necesidad de ayuda. ("Informe de la psicóloga", julio de 1975. Caja 20. Educación. Archivo CAREF).

Este informe resulta interesante porque la brevedad del tiempo evaluado no le impidió realizar un diagnóstico alarmante: "personalidad esquizoide", al tiempo que la "desconexión", y las "fantasías" persecutorias parecieran no tener ninguna relación con el exilio mismo. Lo primero que nos preguntamos es hasta qué punto se trataba de fantasías cuando la persecución era una dimensión real de la vida en los refugios, situación que también podría explicar por qué algunas familias refugiadas podían no sentir especial agradecimiento, aun por quienes, en efecto, los estaban ayudando. Igualmente, encontramos cierta incongruencia entre una descripción que extiende la ansiedad a todo el grupo familiar y la supuesta causa del malestar del niño en su personalidad "enferma".

Informe psicodiagnóstico de Jorge:

Personalidad de tipo esquizoide. Jorge utiliza mecanismos de negación obsesivos y maníacos para evitar que toda su agresión salga en momentos inoportunos: pero la saca de noche, donde se pelea, como quisiera hacerlo de día. (...) Está desubicado en la escuela porque perdió dos años y los chicos de su edad están intelectualmente más elevados que él. No comprende lo que estudia porque le falta recuperar los dos años perdidos. ("Informe de la psicóloga", s/fecha. Caja 20. Educación. Archivo CAREF).

En este otro caso se repite el patrón. La agresividad, de acuerdo con el informe, pareciera explicarse menos como consecuencia de esos dos años en los que el niño interrumpió la escolaridad, que por la personalidad esquizoide. Sin embargo, y a pesar de todos los problemas de integración que describe, se omite un dato interesante: Jorge no elegía la escuela para darle rienda suelta a los episodios de violencia. Él se peleaba de noche. ¿Acaso la escuela se había vuelto un lugar para cuidar?

Informe de Soledad

Es una niña con personalidad esquizoide, que se defiende de la ansiedad persecutoria que siente lentificándose para no explotar. Toda la agresión está dirigida hacia adentro, es entonces que le dan ataques (por ejemplo cuando se separó de su papá) o si no, no puede producir, aprender rendir nada. ("Informe de la psicóloga”, s/fecha. Caja 20. Educación. Archivo CAREF).

La lectura de este informe también resulta interesante y nos permite preguntarnos si existen niños o niñas que tramiten la separación (pérdida) de alguno de sus padres sin manifestar alteraciones de algún tipo. Acaso la desadaptación de estos niños no podría interpretarse como un signo de "equilibrio". Acaso no podríamos suponer que lo problemático, lo excepcional sería suponer que estos niños se integrarían sin mayores conflictos.

Entonces, ¿tantos niños eran esquizoides? Desde luego la pregunta es retórica y pensamos que no. Sostenemos que este tipo de informes revelan la persistencia en el ámbito escolar de una tendencia a considerar las dificultades de integración de los niños como patologías que debían ser resueltas por terapias psicológicas consideradas como mecanismos para adaptar lo desadaptado, en línea con los marcos "psi" muy en boga. ${ }^{15}$ En consecuencia, observamos que los enfoques teóricos que ponían el acento en los contextos sociales para explicar las dificultades infantiles coexistían con otros que tendían a borrar las circunstancias 
políticas y sociales para interpretar las dificultades como patologías a ser tratadas de acuerdo con métodos científicos, en este caso, los proporcionados por la psicología. Por esta vía, la escuela, el mundo de los adultos, educadores y psicólogos quedaban eximidos de responsabilidad frente a la dificultad para integrar a los niños y niñas. De esta manera, la desadaptación, una de las formas más problemáticas en la que se manifestaba el exilio infantil, quedaba desencajada de la matriz que la producía para ser considerada como una cualidad de índole individual.

\section{CONSIDERACIONES FINALES}

Este trabajo es una primera aproximación al análisis de la infancia chilena refugiada en Buenos Aires. En este caso, analizamos el caso de los que asistieron a la escuela de Villa Mitre como parte de un acuerdo entre la institución y CAREF para resolver el problema de la escolarización y contribuir a fortalecer lazos de socialización afectuosos.

De la lectura de las fuentes hemos podido comprobar que la política pública represiva y expulsiva que caracterizó tanto al tercer gobierno peronista (en sus últimos dos años) como a la dictadura militar tuvo efectos resonantes sobre la vida de los niños refugiados que habían llegado al país, ya habiendo sufrido las consecuencias de la dictadura en Chile. La imposibilidad de quedarse en Argentina fue uno de los condicionantes más fuertes que operó contra la integración de los niños a los que se les negó la posibilidad de construir una nueva pertenencia. El drama del desarraigo, por tanto, atravesó buena parte de la infancia de este grupo en el exilio debiendo primero cortar amarras con el lugar de origen y, luego, intentar adaptarse a un lugar del que sabían debían irse al poco tiempo. Asimismo, muchos de los síntomas que vuelcan los informes se conectan con los efectos de la vida en los refugios real y potencialmente amenazada por los allanamientos policiales.

Por otro lado, el análisis de las fuentes nos permite observar que alrededor de CAREF orbitó una red de instituciones preocupadas por transformar la vida en el exilio en una experiencia estimulante y contenedora. Pensamos que la escuela, en este caso, consiguió funcionar como un lugar seguro, en el cual los niños podían materializar con libertad sus temores y angustias. Un proyecto doblemente valioso si subrayamos que se desenvolvió en el contexto del terrorismo de Estado y que nos muestra cómo la historia también se escribe en y con las paradojas. La mayoría de los infantes que había llegado a nuestro país arrastraban trayectorias educativas deficientes, y fue la condición del exilio la que puso en juego la posibilidad de acceder a una educación que, quizás, era de mayor calidad que la que habían tenido en el pasado.

Con todo, en este trabajo también avanzamos en un análisis acerca de las representaciones y prácticas escolares con relación a los niños refugiados. Hemos visto que la influencia de las pedagogías críticas, tan en boga en los años 1960 y 1970, proporcionaron un marco adecuado para encarar los desafíos de integrar a un grupo que homogéneamente atravesaba por situaciones de violencia. Es desde estos enfoques que deben entenderse las iniciativas escolares como las asambleas, que buscaban proporcionar espacios de participación infantil y de integración de los grupos. Aunque, al mismo tiempo, también observamos la escasez de registros que pusieran en cuestión la praxis de los adultos. Uno de los aspectos que más delata la persistencia de la tendencia a considerar la desadaptación infantil como patología son los informes psicológicos y los excesos de diagnósticos.

El carácter inacabado de este trabajo, entonces, nos permite asomarnos al exilio infantil desde nuevas ópticas que consideren a los niños como protagonistas de su propia experiencia, y no solo hijos o hijas de un sujeto adulto exiliado. Si el mundo de la niñez no transita exactamente por los mismos canales que el de los adultos, sería injusto suponer que la experiencia infantil es un mero reflejo de la de sus padres o adultos a cargo; y si la escuela es el lugar por excelencia en el que se manifiesta el protagonismo, la autonomía y la singularidad infantil surge entonces la pregunta: ¿en qué medida el contexto represivo y el paradigma expulsivo reservado para los exiliados permeó las instituciones educativas? ¿En qué otro sentido las escuelas pudieron operar como 
un factor de contención efectiva y transformación subjetiva de los niños? El caso registrado aquí fue muy particular y con toda su relevancia, sus alcances y sus límites, permite renovar el interés por la pregunta.

\section{ReFERENCIAS}

Alcoba, L. (2013). El azul de las abejas. Buenos Aires: Edhasa.

Azconegui, C. (2014). Chilenos en Argentina, entre la protección del Alto Comisionado de las Naciones Unidas para los Refugiados (ACNUR) y la política de expulsión de la dictadura militar. En S. Jensen y S. Lastra (Editoras), Exilio, represión y militancia. Nuevas fuentes y nuevas formas de abordaje de los destierros de la Argentina de los años setenta (pp. 215-250). La Plata: Editorial de la Universidad de la Plata.

Bastian, J. P. (1994). Protestantismo y modernidad latinoamericana. México: FCE.

Bazterrica, A., Montañez, S. y Scapusio, M. (1989). Yo nací allá, yo nací acá, yo qué sé dónde nací. Acerca de un Taller grupal con niños desexiliados. Revista Universitaria, 1.

Brugaletta, F. (2017). El protestantismo y la circulación de la pedagogía de Paulo Freire en América Latina. Revista de Pedagogía Critica, 17, 21-40. Recuperado de http://revistas.academia.cl/index.php/pfr/article/view/535

Burgos Fonseca, M. I. (2018). Feminismos y Exilios. Genealogías del Feminismo Latinoamericano. En S. Lastra (Comp.), Exilios, un campo en expansión (pp. 223-235). Buenos Aires: FLACSO. Recuperado de http://www. memoria.fahce.unlp.edu.ar/libros/pm.622/pm.622.pdf

Casola, N. (2017). Los indeseables. El exilio chileno en la mirada de la DIPBA (1973-1983). Clepsidra. Revista Interdisciplinaria de Estudios sobre Memoria, 4(7), 50-67. Recuperado de http://ppct.caicyt.gov.ar/index.php/ clepsidra/article/view/Casola.

Casola, N. (2017a). La represión estatal hacia los exiliados chilenos entre 1973 y 1983. La construcción de una legalidad represiva para la expulsión. Revista Estudios, 38, 69-86. Recuperado de https://revistas.unc.edu.ar/index.php/r estudios/article/view/19129.

Castillo-Gallardo, P. E. y González-Celis, A. (2015). Infancia, dictadura y resistencia: hijos e hijas de la izquierda chilena (1973-1989). Revista Latinoamericana de Ciencias Sociales, Niñez y Juventud, 13(2), 907-921. Recuperado de http://www.scielo.org.co/pdf/rlcs/v13n2/v13n2a26.pdf.

Cicogna, M. P. (2009). Breve historia de los refugiados en Argentina durante el siglo XX. Historia Actual, 18, 51-63. Recuperado de https://dialnet.unirioja.es/descarga/articulo/3065952.pdf.

González de Oleaga, M., Meloni González, C. y Saigh Dorín, A. (2016). Infancia, exilio y memoria. Tres relatos de una infancia transterrada tras la última dictadura argentina. Kamchatka, 8, 93-109. Recuperado de https://ojs.uv.e s/index.php/kamchatka/article/view/9073/8724.

Gudelevicius, M. (2012). Un análisis de la política educativa para el nivel primario implementada en la Ciudad de Buenos Aires durante la última dictadura argentina (1976-1983) (Tesis de Doctorado Mención en Historia). Buenos Aires, FFy L-UBA, Mimeo.

Jensen, S. (2002). Los hijos del exilio. Reflexiones en torno al diálogo intergeneracional en el seno de las familias argentinas exiliadas en Cataluña. Memory Across Generations: The future of "Never Again". Buenos Aires: Conference sponsored by the University of Wisconsin-Madison \& IDES.

Lértora Mendoza, C. (2015). Las Iglesias Cristianas Reformadas en Argentina: una historia reciente. Anuario de Historia de la Iglesia, 24, 47-72. Recuperado de https://www.unav.edu/publicaciones/revistas/index.php/anua rio-de-historia-iglesia/article/view/1919/1786.

Loutereau, L. (2018). Más crianza y menos terapia. Buenos Aires: Siglo XXI.

Pineau, P. y Mariño, M. (2006). El principio del fin. Buenos Aires: Colihue.

Porta, C. (2006). La segunda generación: los hijos del exilio. En S. Dutrénit Bielous (Coord.), El Uruguay del exilio. Gente, circunstancias y escenarios (pp. 488-505). Montevideo: Trilce.

Puiggros, A. (2003). Quépasó en la educación: breve historia desde la conquista hasta el presente. Buenos Aires: Galerna. Recuperado de http://lenguasvivas.org/campus/files/0_1/92536811-Adriana-Puiggros.pdf. 
Rodríguez, L. G. (2012). Civiles y militares en la última dictadura (1976-1983). Rosario: Prohistoria.

Roselli, N. (2012). La psicología de la educación en Argentina. Raíces, desarrollos y perspectivas. Revista de Psicología Universidad de Antioquia, 4, 103-108. Recuperado de http://aprendeenlinea.udea.edu.co/revistas/index.php/p sicologia/article/view/15484.

Triquell, A. (2012). Fotografias e Historias. La construcción narrativa de la memoria y las identidades en el álbum fotográfico familiar. Montevideo: Centro de Fotografía de Montevideo. Recuperado de https://issuu.com/cmd f/docs/libro_investigacion-con_tapa.

Zaccagnini, M. C. (2003). Impacto de los paradigmas pedagógicos históricos en las prácticas educativas contemporáneas. Revista Iberoamericana De Educación, 33(2), 1-29. Recuperado de https://rieoei.org/RIE/ar ticle/view/2982.

Zucker, C. (2005). La casita de caramelo. Lucha Armada en la Argentina, 3, 4-13.

\section{Notas}

1 Un elemento importante a tomar en cuenta es que el Estado argentino no reconocía a los recién llegados como "refugiados". Si bien Argentina era signataria de la Convención de 1951 de las Naciones Unidas y del Protocolo de 1967 sobre el Status de Refugiados, había adherido manteniendo la limitación geográfica y reconociendo como tales únicamente a personas afectadas por acontecimientos que ocurrieran en Europa (Cicogna, 2009). Es decir, los refugiados lo eran únicamente ante el Alto Comisionado de las Naciones Unidas para los Refugiados (ACNUR).

2 Con relación a la infancia en los exilios del Cono Sur, véase, entre otros: Bazterrica, Montañez y Scapusio (1989); Jensen (2002); Zucker (2005); Porta (2006); Alcoba (2013); Castillo Gallardo y Gonzalez Celis (2015) y González de Oleaga, Meloni González y Saigh Dorín (2016).

3 Optamos por utilizar el concepto niñez exiliada en lugar de hijos e hijas de exiliados justamente para reforzar la especificidad de la experiencia infantil y su contraste con la del mundo de los adultos.

4 Varios especialistas señalan la tristeza infantil aparece cuando se quiebran los espacios de estabilidad que otros pueden darle y son forzados a una madurez precipitada. Como afirma Loutereau (2018, p. 160), "Lo primero que pierde un niño triste en la curiosidad y la curiosidad es la característica propia de lo infantil". Entonces, con la expresión "recuperar la infancia" queremos significar que la escuela buscaba ofrecer un espacio de estabilidad en el que lo lúdico estuviera garantizado como condición esencial para el desarrollo pleno de la subjetividad de los niños y niñas refugiadas.

5 Existe consenso ente los estudiosos de la educación en destacar que, junto con los mecanismos de control, censura y represión, también el régimen militar buscó imponer cambios en los procesos de enseñanza. Sin embargo, gran parte de la historiografía, en especial en los últimos años, también ha puesto énfasis en que estas políticas educativas no lograron imponerse como un bloque homogéneo y produjeron resultados y respuestas diferentes. Véase, Rodríguez (2012) y Gudelevicius (2012).

6 En términos más precisos, esta orientación persecutoria se materializó en un archipiélago de mecanismos represivos de distinto carácter y tenor. Junto con los mecanismos "legales" (cancelación de las posibilidades para conseguir la radicación, extensión de los arrestos y de los decretos de expulsión) comenzó a instalarse la persecución policial "legalizada" y la paraestatal, abiertamente ilegal. Es en este periodo que se concentran la mayoría de las operaciones de coordinación represiva características del Plan Cóndor.

7 A los fines de nuestro objetivo específico, la acción de CAREF, importa reconocer solo el lugar de las iglesias "históricas", es decir, las asociadas al polo liberacionista, de filiación ideológica liberal-modernista. Hasta la primera mitad del siglo XX la mayoría de estas iglesias habían sido promotoras del pensamiento liberal en su gran mayoría de inspiración norteamericana. Eran antiautoritarias, anticatólicas y consideraban que el desarrollo vendría de la mano de una mayor democratización de la vida política. Sin embargo, luego de la Segunda Guerra Mundial y con el inicio de la Guerra Fría, el protestantismo histórico latinoamericano se escindió en dos proyectos divergentes: una tendencia "ecuménica" y otra fundamentalista y evangélica que se identificó con la lucha contra la "amenaza comunista". Dentro del campo ecuménico, varios intelectuales comenzaron a postular la necesidad de una interpretación teológica acorde con la realidad de América Latina. Ese grupo, minoritario, paulatinamente fue convergiendo con la Teología de la Liberación y, entre otras acciones, promoverá la conformación de CAREF. Para una descripción más detallada del mundo protestante en América Latina, véase, Bastian (1994). Para una descripción en el plano nacional, véase, Lértora Mendoza (2015).

8 Una nueva etapa se abrió con el golpe de Estado de 1976. Durante los primeros días, la violencia se desenvolvió con fuerza y se tradujo en operativos perpetrados por el propio Ejército. Sin embargo, luego de ese momento inicial, la dictadura se definió por una orientación política que denotaba preocupación por darle un marco legal a los exiliados del Cono Sur, ya que ahí estaba uno de los primeros focos de la denuncia internacional. 
9 La escolarización de los adolescentes fue menos problemática porque se trataba de un segmento etario minoritario. La mayoría de los y las exiliadas eran muy jóvenes, de manera que, o bien traían niños pequeños, o bien llegaban sin familia a cargo. Para los secundarios, por tanto, cuando resultaba imposible incorporarlos al circuito de escolaridad oficial se intentaba ocuparlos en cursos técnicos cortos que les permitiera aprender algún oficio o habilidad para insertarse laboralmente.

10 Como señala Bastian, la mayoría de las escuelas protestantes solían construirse al costado del templo (Bastian, 1994, p. 129).

11 La Iglesia Discípulos de Cristo forma parte de las iglesias protestantes denominadas "históricas". Surgió a partir de un movimiento de comienzos del siglo XIX con orígenes en el Reino Unido y los Estados Unidos. A través del movimiento misionero del siglo XIX, fueron fundadas en otros lugares del mundo. En Argentina de los años 1960 los Discípulos de Cristo quedaron alineados dentro del grupo de iglesias que abrazaron el ecumenismo y algunos de sus integrantes participaron de la agrupación Iglesia y Sociedad en América Latina (ISAL), que funcionó entre 1961 y 1975. ISAL fue el intento más serio de diálogo con el marxismo.

12 Un ejemplo lo ofrece la obra de Willian Morris, inmigrante inglés, fundador de hogares de niños y pastor evangélico quien desde 1905 creó una red de escuelas evangélicas a finales del siglo XIX, donde se educaron a miles de niños que no estaban escolarizados de los barrios pobres de La Boca, Palermo o Maldonado.

13 Se denomina pedagogías críticas a un conjunto de prácticas y apuestas pedagógicas alternativas que tienen como propuesta que la enseñanza permita cuestionar la dominación, así como las creencias y las prácticas que la generan. En La Pedagogía del Oprimido (1970), Freire plantea una renovación total de la sociedad y parte de la idea de que el conocimiento se gesta desde la interacción social.

14 El normalismo es uno de los paradigmas más influentes en la historia de la educación. En nuestro país surge a fines del siglo XIX en el contexto de consolidación del Estado nacional. En este enfoque el control social y la homogeneización cultural se transforman en los ejes prioritarios de la agenda política de la época tensionada por el principio de "civilización o barbarie". En ese contexto la psicología no sólo contribuyó a la educación con las leyes regulatorias de los procesos psíquicos y del desarrollo, también aportó los instrumentos psicométricos para medir "objetivamente" la inteligencia. Esta visión configuró un tipo particular de intervención de los psicólogos en el marco de instituciones educativas, limitada a la atención de los "casos problema", (Roselli, 2012, p. 105).

15 Si bien la historia de los equipos de orientación escolar se remontaba a principios de los años 1950, fue a partir de la década siguiente que se produjo la expansión en numerosos ámbitos institucionales, principalmente en la enseñanza primaria (Zaccagnini, 2003). Ese diálogo entre psicología y educación tendió a interrumpirse o ralentizarse durante los periodos dictatoriales (1966-1973 y 1976-1983) que vieron en la psicología una herramienta de la "subversión". Con todo, lo cierto es que las primeras experiencias de conexión entre ambos mundos tendió a darse a partir de la patologización de los comportamientos infantiles. 